\title{
Feeding behaviour in dairy cows with and without the influence of clinical diseases or subclinical disorders
}

\author{
Julia Dollinger and Otto Kaufmann \\ Division of Animal Husbandry and Technology, Department of Plant-and Animal Sciences, Faculty of Agriculture and \\ Horticulture, Humboldt-University of Berlin, Berlin, Germany
}

\begin{abstract}
The objective of this study was to describe and compare circadian pattern of feed intake and feeding behaviour in healthy and diseased dairy cows. Test animals $(n=138)$ were separated into two groups according to their health status. Health and management data were used to exclude cows with clinical or subclinical diseases. Fifteen cows of the test herd complied with the defined criteria and formed the reference group »healthy«. The behaviour of the remaining 123 cows was compared with the reference group. Both groups were used to analyse the feed intake and feeding behaviour on a daily base and in the course of $24 \mathrm{~h}$. During a defined time range from day 28 post-partum to day 56 post-partum behavioural differences within these groups were analysed. There were no significant differences in daily feed intake ( 40.7 vs. $41.9 \mathrm{~kg}$ fresh matter per day, $P=0.42$ ). However, feeding behaviour pattern differed between the two groups (daily feeder visits, daily feeding time, number of daily feeder visit, number of daily meals, meal duration, feeding time within a meal, feeder visits per meal). For example, average feeder visit was shorter in the group with subclinical/ clinical health disorders than in the reference group (7.2 vs. $8.1 \mathrm{~min}, P=0.024)$. Differences in circadian feeding behaviour could be detected by analysing the feed intake and feeding time over the course of the day. Linear regression analyses showed strong correlations between feeding time and feed intake on hourly base $\left(R^{2}=0.8\right)$ and on daily base $\left(R^{2}=0.7\right)$.
\end{abstract}

Keywords: feeding behaviour, feed intake, circadian rhythm, subclinical disease, dairy cow

Abbreviations: DM: dry matter, $\mathrm{R}^{2}$ : coefficient of determination, SD: standard deviation

Archiv Tierzucht 56 (2013) 14, 149-159

doi: 10.7482/0003-9438-56-014

Corresponding author:

Julia Dollinger; email: dollinger.j@googlemail.com

Division of Animal Husbandry and Technology, Department of Plant-and Animal Sciences, Faculty of Agriculture and Horticulture, Humboldt-University of Berlin, Philippstr. 13, House 10, D-10115 Berlin, Germany

() 2013 by the authors; licensee Leibniz Institute for Farm Animal Biology (FBN), Dummerstorf, Germany. This is an Open Access article distributed under the terms and conditions of the Creative Commons Attribution 3.0 License (http://creativecommons.org/licenses/by/3.0/).
Received: 10 February 2012

Accepted: 13 June 2012 Online: 1 March 2013 


\section{Introduction}

Health problems in high yielding dairy cows are a very present problem in dairy farming. Health disorders are always attended by restrictions of animal welfare, which has become an important decision criterion for consumers. But diseases in dairy cows do not only affect animal welfare, they also lead to production and quality losses and demand cost-intensive veterinary treatments (Gonzales et al. 2008).

\section{Transit period and early lactation}

Especially during the transit period and in early lactation (approx. week 3 ante-partum till week 8 post-partum), cows are at highest risk for metabolic and infectious disease (Ingvartsen et al. 2003). The cows have to cope with a series of nutritional, physiological, and social changes, which make them more vulnerable to infectious and metabolic disorders (Goff \& Horst 1997). One of the major challenges is to obtain sufficient energy intake to support the onset of lactation, especially impeded by the fact, that feed intake tends to be suppressed around the time of calving (Drackley 1999).

Engelhard \& Zarwel (2005) studied the development of milk production and feed intake from 1996 to 2003. They reported that the milk yield during the first month of lactation increased from $37.4 \mathrm{~kg}$ per day to $42.2 \mathrm{~kg}$ per day within these seven years. This $13 \%$ increase in milk yield stood in contrast to a mere $6 \%$ increase in feed intake from 1996 to 2003. DM intake of cows gradually decreases during the final weeks of gestation (Bertics et al. 1992, Curtis et al. 1985). However, the following early lactation generates an enormous increase in nutrient demands, especially in high-yielding dairy cows. DM intake (and consequently feeding behaviour) increases continuously post-partum and reaches its maximum approx. eight weeks post-partum (Ingvartsen \& Andersen 2000). This lag between energy output from milk yield and energy input from feed intake leads to a negative energy balance. As a response to negative energy balance with low concentration of glucose and insulin in serum, cows will mobilize adipose tissue which leads to increasing serum concentrations of non-esterified fatty acids and $\beta$-hydroxy butyrate. Negative energy balance and attended changes in metabolism are strongly associated with peripaturient disorders (Jorritsma et al. 2003, Bobe et al. 2004). So, inadequate nutrition is likely to contribute to a depression of the immune system and a negative energy balance is an established risk factor for health disorders.

Thereby, health disorders in transition period and early lactation are the cause of important economic loss for producers and represent a serious welfare issue affecting dairy cows (von Keyserlingk et al. 2009).

\section{Behaviour studies}

Concerning these factors, an early detection of health disorders is eligible to reduce production costs and to preserve animal health. There are various approaches to develop early alert systems, e.g. interpretation of milk contents or measuring cows' activity (Edwards \& Tozer 2004, Frost et al. 1997). Recently, various studies accumulated evidences that illness in dairy cows can be identified and predicted by changes in behavioural patterns, in 
particular in feeding behaviour (e.g., Azizi 2008, Huzzey et al. 2007, Krause \& Oetzel 2006, Owens et al. 1998). Therefore, feed intake and feeding behaviour has become an interesting field of research. On the one hand ethological fundamental research such as the analyses of feeding behaviour meets numerous interests: to evaluate behavioural response to stress, to determine adaptive range within genetic groups to changing environments, and to determine regulating behaviour (Arave \& Albright 1981). On the other hand, several studies showed that feed intake and feeding behaviour are influenced by the presence of disease. Therefore, analyses of feed intake and feeding behaviour seem to offer good prospects for the early identification of health problems in dairy cows.

\section{Pattern of feed intake and feeding behaviour}

To describe feed intake in dairy cows the generally used time unit is the $24 \mathrm{~h}$ day (Stamer et al. 1997). The typical characteristics of feeding behaviour are the number of visits at the feeder per day, visit duration, and daily feeding time. Concerning the quantitative feed intake, the characteristics feed intake per day, feed intake per visit and feeding rate are used. However, it is reasonable to focus not only on the visits as the decisive characteristic. Tolkamp et al. (1998) and Tolkamp \& Kyriazakis (1999) developed a method to describe feeding behaviour with satiety mechanism and to cluster feeding events into meals. The idea of satiety is that the probability that a cow will initiate a meal dependents on the time past since the last meal (Metz 1975). As the duration of non-feeding increases, hunger motivation will increase the likelihood of starting a new meal (Tolkamp et al. 2000). The meal criterion has been defined as the longest non-feeding interval that is still regarded as an interval within a meal (Tolkamp et al. 1998, Yeates et al. 2001). In consideration of the meal concept, following feeding characteristics have to be added to the previously mentioned ones: number of meals, meal duration, and feed intake per meal.

\section{Influences on feed intake and feeding behaviour}

Focusing on feeding behaviour, there have been various studies to detect the main influence factors in modern dairy cow housing systems. Huzzey et al. (2007) detected a decrease in feeding time in cows developing clinical metritis. A further study focussing on ketotic cows in early lactation, showed changes in feed intake and feeding behaviour which occurred at an average of 3.6 days before diagnosis (Gonzales et al. 2008). In this study, sick cows reduced the daily feed intake $(-10.4 \mathrm{~kg} \mathrm{DM})$, daily feeding time $(-45.5 \mathrm{~min})$, and feeding rate $(-25.3 \mathrm{~g}$ $\left.\mathrm{DM} \mathrm{min}^{-1}\right)$. Feeding behaviour is also influenced by lameness. Cows with claw horn lesions consumed feed at a faster rate $\left(86 \pm 3\right.$ vs. $\left.77 \pm 3 \mathrm{~g} \mathrm{~min}^{-1}\right)$ compared to cows without lesions (Proudfoot et al. 2010). But not only clinical diseases cause changes in feeding behaviour, also subclinical disorders have an impact on cows' behaviour: Azizi (2008) collected data on feeding behaviour characteristics, feed intake, and milk production of 47 German Holstein Frisian cows from day 7 to day 105 of lactation. Eight cows with pathological findings in blood counts (raised concentration of non-esterified fatty acids, $\beta$-hydroxy butyrate, and aspartate amino transferase), but without any clinical problems were compared with cows without clinical or subclinical disorders. Cows with subclinical metabolic disorders had lower meal duration, daily mealtime, meal size, and daily DM intake than cows without subclinical 
metabolic disorders during the second and third week of lactation. Beside health disorders, management factors such as feeding system design, feed delivery, and resource competition as well as individual factors (social hierarchy and parity) have a strong influence on feeding behaviour pattern (Grant \& Albright 2000, DeVries et al. 2003b, Azizi et al. 2009).

\section{Circadian behaviour}

To anticipate daily changes in environment (e.g. light, nutrient availability or the presence of predators) most organisms possess a circadian timing. As a central circadian pacemaker the suprachiasmatic nuclei in the hypothalamus has been identified (Ralph et al. 1990). The circadian rhythm of feed intake in modern housing systems is strongly affected by feed delivery and milking times. Studies on feeding behaviour focus mainly on summarizing feeding characteristics in a $24 \mathrm{~h}$ period. There have been only few studies focusing on how lactating cows pattern their feed intake during the course of day (Wagner-Storch \& Palmer 2003, DeVries et al. 2003b). DeVries et al. (2003b) described the diurnal variations in feed alley attendance patterns of lactating dairy cows.

In consideration of the varying influences, fundamental research on »normal« feeding behaviour of dairy cows is essential, in particular in the absence of internal stressors such as disease or heat. For this reason, the objectives of this research were to:

1) describe patterns of feed intake and feeding behaviour of healthy lactating cows during the course of day without being influenced by health disorders and

2) compare feeding behaviour of healthy cows and those who suffer from clinical disease or show pathological blood/urine counts, and

3) analyse the correlations between feeding time and feed intake.

\section{Material and methods}

The experiment was carried out at the Centre of Animal Husbandry and Technology of the Regional Office for Agriculture and Horticulture in Iden, Saxony-Anhalt, Germany, between December 2007 and March 2009. The primary aim of the experiment was to analyse the effect of two total mixed rations with differing amounts of concentrate. Thus no differences in fresh matter intake was found, both groups were analysed in our study.

\section{Animals, housing and feeding}

Feeding behaviour and feed intake data of 138 primiparous and multiparous (parity 3.1 \pm 1.4 [mean \pm SD]) lactating cows were collected using an electronic feeding system. 15 German Holstein cows out of these 138 were chosen for analysis by reasons of health status. For a detailed description see chapter Statistics. All cows were kept in a cubicle barn with a cow feeder ratio of 2:1. There was continuous access to the feeders except from 7.00 to 8.00 , when food residues were removed from the troughs and fresh feed was supplied. Feeders were also closed from 22.30 to 24.00 to transfer data. Cows were fed ad libitum twice a day (8.00 and 13.00) with a total mixed ration with an average of $7.00 \mathrm{MJ} \mathrm{NEL} \mathrm{kg} \mathrm{DM}^{-1}, 155 \mathrm{~g}$ crude protein $\mathrm{kg} \mathrm{DM}^{-1}, 200 \mathrm{~g}$ acid detergent fibre $\mathrm{kg} \mathrm{DM}^{-1}$, and $343 \mathrm{~g}$ neutral detergent fibre $\mathrm{kg} \mathrm{DM}^{-1}$. Cows were milked three times a day $(4.00,12.00$, and 20.00$)$ with an average daily milk yield of $40.5 \pm 8.3 \mathrm{~kg}, 4.04 \pm 0.66 \%$ fat, and $3.26 \pm 0.27 \%$ protein. 


\section{Measurements and preparation of data}

Feeder units included individual electronic identification systems and load sensing equipment to measure each cow's feeder visit start time and end time as well as the feed intake. A feeder visit was defined as times spend by an individual cow with her head in one of the troughs. Intervals between visits were calculated for each cow from the end time of a visit and the start time of the next. The automatic feeders measured intervals between visits to the feeder with the precision of $1 \mathrm{~s}$. To determine if a visit was part of the previous meal, part of the next meal or formed a meal itself, visits were clustered into meals based on a pooled meal criterion for all cows over the whole course of the study. The meal criterion was calculated based on methods established by Tolkamp et al. (1998) and DeVries et al. (2003a). Feed intake was calculated as the difference between troughs weight at the beginning and the end of a visit.

\section{Health data and blood sampling}

Veterinary treatments and separation of cows due to lameness or other health problems were documented by farm staff. Individual blood samples were selected four times in early lactation focussing on parameters showing metabolism disorders: day 1-5 post-partum, day 14 postpartum, day 28 post-partum, and day 56 post-partum. Individual urine samples were collected three times in early lactation: day 14 post-partum, day 28 post-partum and day 56 post-partum. Analysed serum and urine parameters are given in Table 1. According to blood/urine count, each cow was individually classified at each sampling day by veterinarians into three categories: (1) without pathological findings, (2) indifferent, and (3) with pathological findings. Classification was carried out according to the reference ranges determined by Fürll (2005).

Table 1

Analysed serum and urine parameters (resp.) and sampling days (Fürll 2005)

\begin{tabular}{|c|c|c|c|c|c|}
\hline & \multirow[t]{2}{*}{ Reference range } & \multicolumn{4}{|c|}{ Sampling day post-partum } \\
\hline & & $1-5$ & 14 & 28 & 56 \\
\hline \multicolumn{6}{|l|}{ Urine } \\
\hline $\mathrm{pH}$ & $7.8-8.4$ & - & $\mathrm{x}$ & $\mathrm{x}$ & $\mathrm{x}$ \\
\hline Netto-acid-base-excretion, $\mathrm{mmol} / \mathrm{l}$ & $83-215$ & - & $\mathrm{x}$ & $\mathrm{x}$ & $\mathrm{x}$ \\
\hline Bases, mmol/l & $150-200$ & - & $\mathrm{x}$ & $\mathrm{x}$ & $\mathrm{x}$ \\
\hline Acids, mmol/l & $50-100$ & - & $x$ & $x$ & $x$ \\
\hline Ammonium $\left(\mathrm{NH}^{+}\right), \mathrm{mmol} / \mathrm{l}$ & $<10$ & - & $x$ & $x$ & $x$ \\
\hline Base-acid-ratio without $\mathrm{NH}^{+}$ & $1.8-4.6$ & - & $\mathrm{x}$ & $\mathrm{x}$ & $\mathrm{x}$ \\
\hline \multicolumn{6}{|l|}{ Serum } \\
\hline Calcium, mmol/l & $2.0-2.5$ & $\mathrm{x}$ & $\mathrm{x}$ & $\mathrm{x}$ & $\mathrm{x}$ \\
\hline Inorg. phosphate, mmol/l & $1.55-2.29$ & $\mathrm{x}$ & $\mathrm{x}$ & $\mathrm{x}$ & $\mathrm{x}$ \\
\hline Magnesium, mmol/l & $0.9-1.32$ & $\mathrm{x}$ & $\mathrm{x}$ & $\mathrm{x}$ & $\mathrm{x}$ \\
\hline Aspartate amino transferase, $\mathrm{U} / \mathrm{l}$ & $<80$ & $\mathrm{x}$ & $\mathrm{x}$ & $\mathrm{x}$ & $\mathrm{x}$ \\
\hline Creatine kinase, U/I & $<150$ & $\mathrm{x}$ & $\mathrm{x}$ & $\mathrm{x}$ & $\mathrm{x}$ \\
\hline Glutamate dehydrogenase, $\mathrm{U} / \mathrm{I}$ & $<30$ & $\mathrm{x}$ & $\mathrm{x}$ & $\mathrm{x}$ & $\mathrm{x}$ \\
\hline$\beta$-hydroxy butyrate, mg/l & $<64$ & $\mathrm{x}$ & $\mathrm{x}$ & $\mathrm{x}$ & $\mathrm{x}$ \\
\hline Total bilirubin, mg/dl & $<0.3$ & $\mathrm{x}$ & $\mathrm{x}$ & $\mathrm{x}$ & $\mathrm{x}$ \\
\hline Blood urea nitrogen, mg/dl & $12-41$ & $\mathrm{x}$ & $\mathrm{x}$ & $\mathrm{x}$ & $\mathrm{x}$ \\
\hline Cholesterol, mg/dl & $>58$ & $\mathrm{x}$ & $\mathrm{x}$ & $\mathrm{x}$ & $\mathrm{x}$ \\
\hline Non-esterified fatty acids, $\mathrm{mmol} / \mathrm{l}$ & $<0.8$ & $\mathrm{x}$ & $\mathrm{x}$ & $\mathrm{x}$ & $\mathrm{x}$ \\
\hline
\end{tabular}

$\mathrm{x}$ : samples were taken, -: no samples were taken 


\section{Selection of reference group and time range}

The aim of this study was to analyse the circadian feed intake and feeding behaviour in healthy dairy cows. Thus, different criteria were used to exclude diseased cows from the reference group: no veterinary treatments from calving to day 70 post-partum, no separation from the herd by farm staff due to health problems from calving to day 70 post-partum, blood status after calving without pathological findings or indifferent, blood status (respectively urine status) day 14 post-partum without pathological findings or indifferent, blood status (respectively urine status) day 28 post-partum and day 56 post-partum without pathological findings. In doing so, we warrant a selection of animals with a maximum likelihood of a good health status (clinical and subclinical). Fifthteen German Holstein cows (parity $3.0 \pm 1.0$ ) complied with these requirements (»healthy«) and were used to analyse the feed intake and feeding behaviour in the course of the day. Out of the residual 123 cows, 32 individuals had to be treated due to clinical diseases, 91 animals showed pathological data in blood or urine counts. We chose the time range for our analyses in middle early lactation, between blood sampling at day 28 post-partum and day 56 post-partum and averaged feeding behaviour and feed intake characteristics for each cow.

\section{Statistics}

SAS v. 9.2 (SAS Institute Inc., Cary, NC, USA) was used to edit and analyse data. Descriptive data analysis was conducted with PROC MEANS and PROC UNIVARIATE. To analyse the relationship between feeding behaviour and feed intake we calculated linear regressions (PROC CORR). ANOVA F option for repeated measures in non-parametric data was used to compare the groups.

\section{Results}

\section{Group comparisons of feeding behaviour and feed intake}

Feeding behaviour parameters and daily feed intake of lactating dairy cows from day 28 postpartum to day 56 post-partum were calculated. Results are given in Table 2. No significant differences were calculated for quantitative feed intake. The animals classified as healthy had less daily feeding time, less number of feeder visits, and less meals per day. In contrast, feeder visits were longer within the reference group, likewise meal duration and feeding time within meals. However, number of feeder visits within a meal was higher in animals with clinical disorders or pathological findings.

\section{Feeding behaviour and feed intake during the course of day}

In Figure 1, feeder visit duration (A) and feed intake (B) over the course of the day in reference group and group with clinical disorders or pathological findings in blood/urine counts are presented. Both groups show similar pattern of feed intake and feeding behaviour, with highest preferences for late afternoon and evening hours. Longest feeder visits were monitored 8.00 and 12.00 (after feed delivery and milking) and from 17.00 to 20.00 . High quantitatively feeding activity was registered after feed delivery and before and after evening milking. 
Table 2

Pattern of feed intake from the defined animal groups from day 28 post-partum to day 56 post-partum

\begin{tabular}{lccc}
\hline & $\begin{array}{c}\text { Reference group } \\
\text { (healthy) }\end{array}$ & $\begin{array}{c}\text { Group with clinical disorders or } \\
\text { pathological findings in } \\
\text { blood and urine count }\end{array}$ & $P$ \\
\hline Cows, n & 15 & 123 & \\
Number of lactation & $3.0( \pm 1.0)$ & $3.1( \pm 1.5)$ & 0.02 \\
Daily feeding characteristics & $177.8( \pm 54.0)$ & $189.4( \pm 53.8)$ & $\mathrm{ns}$ \\
$\quad$ Daily feeding time, min & $40.7( \pm 9.1)$ & $41.9( \pm 9.1)$ & 0.0008 \\
Daily feed intake, kg FM & $21.9( \pm 10.5)$ & $26.4( \pm 11.9)$ & 0.0004 \\
Daily feeder visits & $6.2( \pm 1.6)$ & $6.9( \pm 2.0)$ & 0.024 \\
Daily meal frequency & & & 0.013 \\
Feeder visit/meal characteristics & $8.1( \pm 7.6)$ & $3.2( \pm 6.9)$ & 0.0002 \\
$\quad$ Feeder visit duration, min & $36.3( \pm 25.5)$ & $27.5( \pm 24.4)$ & $<0.0001$ \\
Meal duration, min & $28.8( \pm 18.4)$ & $3.5( \pm 2.7)$ & \\
Feeding time within a meal, min & $3.3( \pm 2.5)$ & & \\
Feeder visits per meal & & & \\
\hline
\end{tabular}
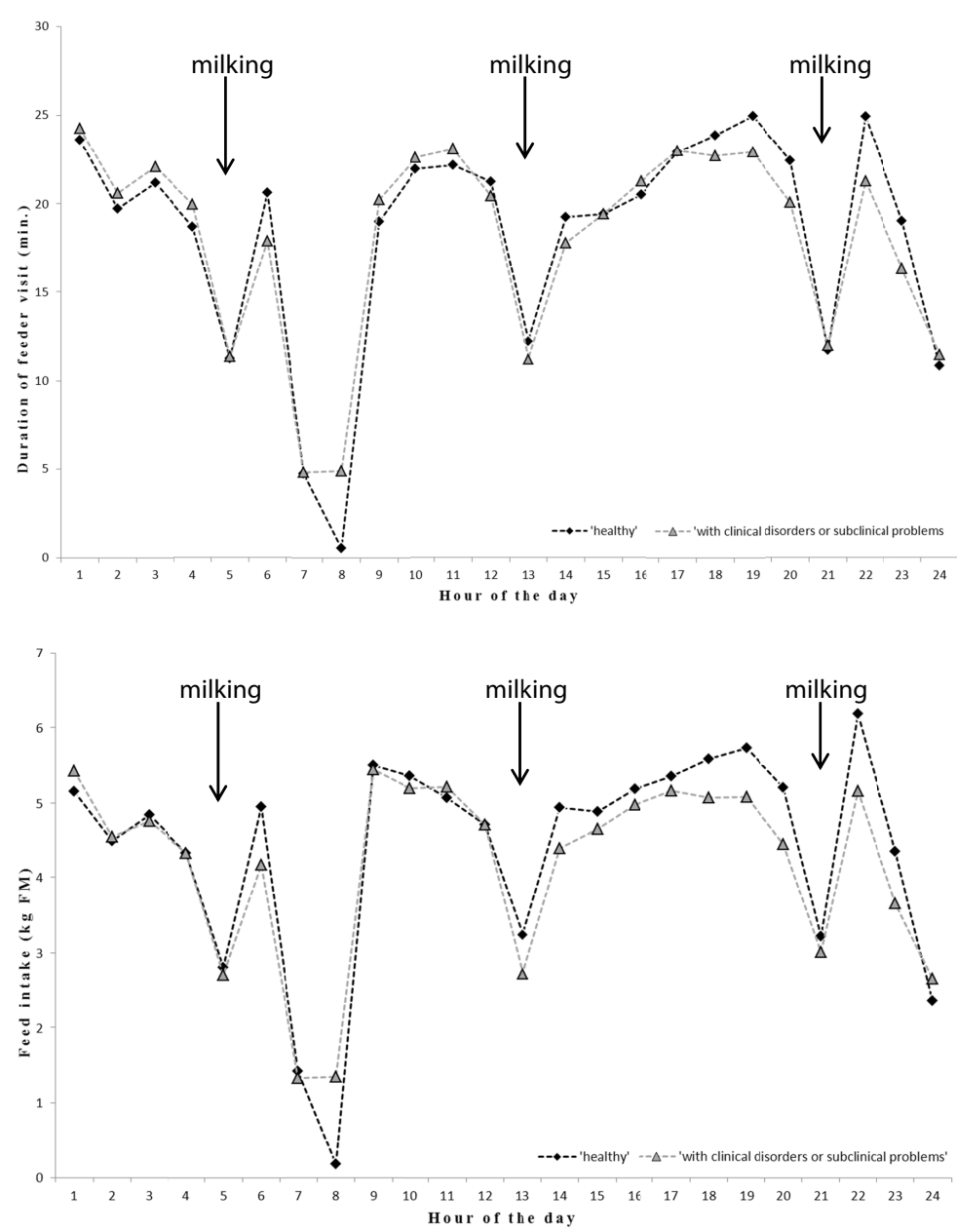

A

B

Figure 1

Interrelations between feeding behaviour and feed intake 
As shown in figure 1, the circadian feeding behaviour over the course of the day shows interesting aspects and differing tendencys between groups. To make circadian behaviour of the groups more comparable with each other, outstanding marks over the course of the day were calculated: The hour of the day, where animals of one group or the other reach $25 \%$ (50\%, 75\%, $100 \%$ resp.) of daily feed intake or daily feeding time. By comparing these marks, significant differences occured: healthy animals tend to reach the defined marks later at the day than cows with clinical disorders or subclinical problems do. This applys to daily feed intake as well as to daily feeding time. Latest feeding activity (100\% mark) was without differences, furthermore this mark is identical for feed intake and feeding time as a matter of course.

To analyse whether qualitative feeding behaviour parameters are an appropriate indicator for quantitative feed intake, regression analyses were conducted. The analysis between feeding behaviour and feed intake of all cows showed a significant positiv correlation $(P<0.0001)$. The coefficient of determination between duration of feeder visit per hour and feed intake per hour was $R^{2}=0.8$ with the regression equation.

$$
\hat{y}=0.51+0.21 x
$$

\section{Discussion}

Knowledge on behaviour pattern of healthy dairy cows is essential to evaluate behavioural response to stress or to accumulate the repertoire of normal animal behaviour as a base for studies on regulation processes (Arave \& Albright 1981). Most results of feeding behaviour characteristic and feed intake parameters obtained in the current study were close to results which had been reported by other researchers (Azizi et al. 2009, DeVries et al. 2003a). Differences in feeding behaviour between the reference group and the animals with clinical disorders/pathological findings in blood/urine counts were significant. The healthy group had less daily feeder visits, less number of meals per day, longer feeder visit duration and longer meal durations. Combining these differences one can assume that there was more agitation and less consistency among the animals with health problems. Those cows might avoid social stress and tend to be easily pushed away from troughs. But whereas healthy cows in the current study showed a meal frequency of $6.2 \pm 1.6$ meals per day, cows with clinical disorders or pathological findings in blood/urine realised $6.9 \pm 2.0$ meals per day. Higher meal frequencies were also reported by DeVries et al. (2003a) with $7.3 \pm 1.5$ meals per day and by Azizi et al. (2009) with a range of 7.2 to 8.7 meals per day depending on parity and milk yield.

Similar pattern within the two groups are visualised over the course of the day (Figure 1). Preferred feeding periods occurred after milking times. The reference group seems to dominate those preferred hours whereas animals with clinical disorders or pathological findings in blood/urine counts tend to benefit from early morning hours. Significant influences of health disorders on cows' behaviour are proven (Gonzales et al. 2008). This fact confirms the approach of selecting healthy animals to define the »normal« behaviour as the base for consecutive studies.

High feeding activity was registered for $\mathrm{h} 1, \mathrm{~h} 9, \mathrm{~h} 19$, and $\mathrm{h} 22$. Those high points could be found in feeding behaviour pattern as well as in quantitative feed intake and meal pattern. 
Apparently highest feeding activity followed closely after scheduled milking times (4.00, 12.00, and 20.00) and before/after closed troughs due to management processes. Despite the wide cow feeder ratio of 2:1, healthy dairy cows seem to strongly favour the feed intake after milking. It is also interesting how strongly cows react on regular processes (milking, trough closing). The strong influence of milking schedule on feeding behaviour pattern was also found by Tolkamp et al. (2000). Similar results were presented by DeVries et al. (2003b) with the greatest percentage of cows attending the feed alley after the delivery of fresh feed and the return from milking.

Significant differences between the studied groups were shown in analysing relative marks in daily feeding behaviour (Table 2). This might also show that cows with clinical disorders or pathological findings in blood/urine counts tend to realise their main feed intake in less favored feeding times to avoid confrontations at the troughs.

To analyse whether feeding duration spent in specific time periods can be an indicator for daily feed intake we had to assure that feeding behaviour is strongly associateted with feed intake. The conducted regression analyses verified these estimations with high significant $(P<0.001)$ results $\left(R^{2}=0.8\right)$. These results show stronger correlations then published in previous studies (Azizi et al. 2010, Kaufmann et al. 2007). Differences can be caused by the use of DM intake in the cited studies while we used fresh matter intake as dependend variable. Varying amount of DM could have strong effects on the results of the cited analyses. But considering to put the application of feeding behaviour analyses into practice, the use of fresh matter as indicated value seems reasonable.

Our analysis shows that healthy cows' feed intake and feeding behaviour over the course of day is geared to milking times, management processes, and individual preferences. Time spent at the feeder is strongly correlated with quantitative feed intake (hour and daily base). Furthermore significant differences in feeding behaviour of healthy cows and those with health disorders could be observed. Cows coping with internal stressors show more activity in feeding. It is expected that renunciations of individual behaviour pattern are attended by changes in feed intake. Therefore, consecutive studies will analyse the relationships between individual behaviour patterns over the course of day and the presence of stressors e.g. subclinical diseases on an individual base.

\section{Acknowledgements}

The authors gratefully thank the staff of the Centre of Animal Husbandry and Technology of the Regional Office for Agriculture and Horticulture in Iden, Saxony-Anhalt, Germany.

\section{References}

Arave CW, Albright JL (1981) Cattle behaviour. J Dairy Sci 64, 1318-1329

Azizi $O$ (2008) Relationships between feeding behaviour and feed intake in dairy cows during early lactation. PhD Thesis, Humboldt-University Berlin, Germany

Azizi O, Hasselmann L, Kaufmann $\mathrm{O}$ (2010) Variations in feeding behaviour of high-yielding dairy cows in relation to parity during early to peak lactation. Arch Tierz 53, 130-140

Azizi O, Kaufmann O, Hasselmann L (2009) Relationship between feeding behaviour and feed intake of dairy cows depending on their parity and milk yield. Livest Sci 122, 156-161 
Bertics SJ, Grummer RR, Cadorniga-Valino C, Stoddard EE (1992) Effect of Prepartum Dry Matter Intake on Liver Triglyceride Concentration and Early Lactation. J Dairy Sci 75, 1914-1922

Bobe G, Young JW, Beitz DC (2004) Pathology, Etiology, Prevention, and Treatment of Fatty Liver in Dairy Cows. J Dairy Sci 87, 3105-3124

Curtis CR, Erb HN, Sniffen CJ, Smith RD, Kronfeld DS (1985) Path Analysis of Dry Period Nutrition, Postpartum Metabolic and Reproductive Disorders, and Mastitis in Hostein Cows. J Dairy Sci 68, 2347-2360

DeVries TJ, von Keyserlink MAG, Weary DM, Beauchemin KA (2003a) Measuring the Feeding Behavior of Lactating Dairy Cows in Early to Peak Lactation. J Dairy Sci 86, 3354-3361

DeVries TJ, von Keyserlingk MAG, Beauchemin KA (2003b). Diurnal Feeding Pattern of Lactating Dairy Cows. J Dairy Sci 86, 4079-4082

Drackley JK (1999) Biology of Dairy Cows During the Transition Period: the Final Frontier? J Dairy Sci 82, 2259-2273

Edwards JL, Tozer PR (2004) Using Activity and Milk Yield as Predictors of Fresh Cow Disorders. J Dairy Sci 87, 524-531

Engelhard T, Zarwel H (2005) [Ways to reduce the rate of reproduction - Practical experience of herd management and experimental results from the dairy herd]. In: 6. Jahrestagung der Wisse. Gesell. der Milcherzeugerberater, Berlin, Germany [in German]

Frost AR, Schofield CP, Beaulah SA, Mottram TT, Lines JA, Wathes CM (1997) A review of livestock monitoring and the need for integrated systems. Comp Electr Agric 17, 139-159

Fürll M (2005) [Special studies in ruminants]. In: Kraft W, Dürr UM (eds) [Clinical laboratory diagnostics in veterinary medicine]. Schattauer Verlag, Stuttgart, Germany, 444-471 [in German]

Goff JP, Horst RL (1997) Physiological Changes at Parturition and Their Relationship to Metabolic Disorders. J Dairy Sci 80, 1260-1268

González LA, Tolkamp BJ, Coffey MP, Ferret A, Kyriazakis I (2008) Changes in Feeding Behaviour as Possible Indicators for the Automatic Monitoring of Health Disorders in Dairy Cows. J Dairy Sci 91, 1017-1028

Grant RJ, Albright JL (2000) Feeding Behaviour. In: D'Mello JPF (ed) Farm Animal Metabolism and Nutrition. CABI Publishing, Wallingford, Oxon, UK, 365-382

Huzzey JM, Veira DM, Weary DM, von Keyserlingk MAG (2007) Prepartum Behaviour and Dry Matter Intake Identify Dairy Cows at Risk for Metritis. J Dairy Sci 90, 3220-3233

Ingvartsen KL, Andersen JB (2000) Integration of Metabolism and Intake Regulation: A Review Focusing on Periparturient Animals. J Dairy Sci 83, 1573-1597

Ingvartsen KL, Dewhurst RJ, Friggens NC (2003) On the relationship between lactational performance and health: is it yield or metabolic imbalance that cause production diseases in dairy cattle? A position paper. Livest Prod Sci 83, 277-308

Jorritsma R, Wensing T, Kruip TAM, Vos PLAM, Noordhuizen JPTM (2003) Metabolic changes in early lactation and impaired reproductive performance in dairy cows. Vet Res 34, 11-26

Kaufmann O, Azizi O, Hasselmann L (2007) [Feeding behaviour of high yielding dairy cows during early lactation.] Züchtungskunde 79, 219-230 [in German]

Krause KM, Oetzel GR (2006) Understanding and preventing subacute ruminal acidosis in dairy herds: A review. Anim Feed Sci Technol 126, 215-236

Metz JHM (1975) Time patterns of feeding and rumination in domestic cattle. PhD Thesis, NL 75-12, Wageningen Agric Univ, Wageningen, The Netherlands

Owens FN, Secrist DS, Hill WJ, Gill DR (1998) Acidosis in cattle: a review. J Anim Sci 76, 275-286

Proudfoot KL, Weary DM, von Keyserlingk MAG (2010) Behavior during transition differs for cows diagnosed with claw horn lesions in mid lactation. J Dairy Sci 93, 3970-3978

Ralph MR, Foster RG, Davis FC, Menaker M (1990) Transplanted Suprachiasmatic Nucleus Determines Circadian Period. Science 247, 975-978 
Stamer E, Junge W, Kalm E (1997) Temporal pattern of feeding behaviour of dairy cows kept in groups. Arch Tierz 40, 195-214

Tolkamp BJ, Allcroft DJ, Austin EJ, Nielsen BL, Kyriazakis I (1998) Satiety Splits Feeding Behaviour into Bouts. J Theor Biol 194, 235-250

Tolkamp BJ, Kyriazakis I (1999) To split behaviour into bouts, log-transform the intervals. Anim Behav 57, 807-817

Tolkamp BJ, Schweitzer DPN, Kyriazakis I (2000) The Biologically Relevant Unit for the Analysis of Short-Term Feeding Behavior of Dairy Cows. J Dairy Sci 83, 2057-2068

Von Keyserlingk MAG, Rushen J, de Passillé AM, Weary DM (2009) Invited review. The welfare of dairy cattle Key concepts and the role of science. J Dairy Sci, 92, 4101-4111

Wagner-Storch AM, Palmer RW (2003) Feeding Behavior, Milking Behavior, and Milk Yields of Cows Milked in a Parlor Versus an Automatic Milking System. J Dairy Sci 86, 1494-1502

Yeates MP, Tolkamp BJ, Allcroft DJ, Kyriazakis I (2001) The use of Mixed Distribution Models to Determine Bout Criteria for Analysis of Animal Behaviour. J Theor Biol 213, 413-425 